\title{
甘肃省生态环境与社会经济系统协调发展的耦合分析
}

\author{
任祁荣 ${ }^{1}$ ，于恩逸 ${ }^{2, *}$ \\ 1 甘肃省生态环境科学设计研究院, 兰州 730000 \\ 2 中国科学院生态环境研究中心,城市与区域生态国家重点实验室,北京 100085
}

摘要:社会经济发展与当地自然生态环境保护之间的耦合协调是可持续发展研究的热点问题。本研究以甘肃省为研究对象,构 建甘肃省自然生态系统与社会经济系统耦合协调度模型及综合评价指标体系,分析甘肃省 2007-2017 年间社会经济发展与自 然生态环境质量变化之间的耦合协调程度及演变过程。结果表明: ( 1) 甘肃省的自然环境质量指数在 2007一-2017 年间呈先波 动下降后逐步上升的变化趋势,而甘肃省社会经济发展水平自然环境系统的综合水平在 2007-2017 年间整体呈现上升趋势; (2) 2007-2017 年,甘肃省的社会经济与自然生态环境质量的发展状态从失调阶段逐步过渡到协调阶段,说明这社会经济系统 与自然生态环境系统的耦合过程正从磨合阶段向着高水平有序状态稳固发展, 10 年间甘肃省生态环境与社会经济发展的耦合 协调性有明显改善。面向自然生态环境质量与社会经济发展速度的动态讨论可以看出:(1) 甘肃省自然环境和社会经济变化 速率的剪刀差的演变过程经过了差异较大但无明显制约一社会经济对生态环境压力逐步加重一社会经济发展与生态支撑能力 同步回升的演变过程; (2)2007-2014 年,甘肃省处于自然生态环境的发展速度小于社会经济的发展速度阶段,社会经济发展 受生态环境的限制和约束,经济发展对生态环境的影响也几乎为零,但其相互胁迫程度不断增加,到 2015一2017 年, 自然生态 环境的发展速度大于社会经济的发展速度,2015-2017 年自然生态环境的增速高于社会经济发展速度,产业结构优化和自然 生态环境保护措施开始起效,社会经济与自然生态环境之间的耦合协调度越来越好。

关键词: 社会经济; 生态环境;综合评价;耦合协调度;甘肃省

\section{Coupling analysis on coordinated development of ecological environment and social economic system in Gansu Province}

REN Qirong' ${ }^{1}$, YU Enyi ${ }^{2}$,*

1 Gansu Academy of Eco-Environmental Sciences, Lanzhou 730000, China

2 State Key Laboratory of Urban and Regional Ecology, Research Center for Eco-Environment Sciences, Chinese Academy of Sciences, Beijing 100085, China

Abstract: The coupling coordination between social economic development and local natural ecological environment protection is a hot topic in sustainable development research. Taking Gansu Province as the research area, this study constructed the coupling coordination degree model and comprehensive evaluation index system of natural ecosystem and social economic system in Gansu Province, and analyzed the coupling coordination degree and evolution process between social and economic development and the change of natural ecological environment quality in Gansu Province from 2007 to 2017. The results show that, (1) From 2007 to 2017, the natural environment quality index of Gansu province fluctuated first and then gradually increased, while the comprehensive level of the natural environment system of Gansu province's social and economic development showed an overall rising trend. (2) The state of the development of social economy and natural ecological environment quality from disorder stage gradually transition to the coordination stage, the social economic

基金项目: 国家重点研发计划资助 (2018YFC0806900)

收稿日期: 2020-09-03; 网络出版日期:2020-12-15

* 通讯作者 Corresponding author.E-mail: eyyu@ rcees.ac.cn 
system and natural ecological environment system of the coupling process is from the running-in stage to stable development of high order, 10 years of ecological environment and social economic development in Gansu Province coupling coordination has improved significantly. It can be seen from the dynamic discussion of natural ecological environment quality and social and economic development speed, (1) the evolution process of scissors difference of natural environment and social and economic change rate in Gansu Province has gone through the evolution process of great difference but no obvious restriction— - the pressure of social economy on ecological environment is increasing gradually-the development of social economy and ecological support ability rise simultaneously. (2) From 2007 to 2014, Gansu Province was at a stage where the development speed of the natural ecological environment was lower than that of the social economy. The social and economic development was restricted and restrained by the ecological environment, and the impact of economic development on the ecological environment was almost zero, however, the degree of mutual stress was increasing. From 2015 to 2017 , the development rate of natural ecological environment will be faster than that of social economy, the growth rate of natural ecological environment was higher than that of social and economic development, industrial structure optimization and natural ecological environment protection measures began to take effect, and the degree of coupling and coordination between social economy and natural ecological environment became better and better.

Key Words : Social-economy; ecological environment; integrated assessment; coupling coordination; Gansu Province

社会经济与生态环境之间的协调发展一直是可持续发展中的重要议题与热点 ${ }^{[1-2]}$, 协调发展要求区域社 会经济发展与自然生态环境状况能够相互促进 ${ }^{[3]}$, 实现耦合协调的共同发展过程 ${ }^{[4]}$ 。近年来, 在社会经济与 生态环境之间相互关系的研究方面,已逐渐从定性分析向定量的趋势评价准备 ${ }^{[5]}$, 并基于不同的概念模型和 不同的研究视角,提出了大量的关于生态环境与社会经济协调、耦合关系的评价模型 ${ }^{[6-7]}$ 。如 PSR 模型从“压 力-状态-响应”的角度分析区域经济活动与生态环境之间的相互关系 ${ }^{[8]}$, 库兹涅茨计量模型通过对经济指标 和环境指标之间的关系模拟是否存在倒“ $U$ ”假说来判定不同区域经济系统与环境系统之间的耦合状态 ${ }^{[9-10]}$, 基于传统系统动力学模型构建的社会经济-生态环境耦合系统动力学模型从系统动力学模拟的角度分析区 域社会经济系统与生态环境系统的耦合动力过程 ${ }^{[11]}$, 还有学者基于耦合理论建立区域经济-环境系统的耦合 度模型分析经济-环境系统关键因子的协调程度 ${ }^{[12-13]}$ 。在研究尺度与研究区域方面, 国内在重点城市群城市 化、社会经济系统与生态环境系统的耦合关系有大量的研究成果 ${ }^{[14-16]}$, 方创琳等对中国城市群的交互耦合效

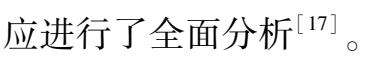

当前对于社会经济与生态环境的研究多面向城市或城市群, 以城市化的过程为主要方面,探索城市化进 程中社会经济发展与生态环境质量间的耦合协调过程。考虑到我国政策体系中省域政策的重要性 ${ }^{[18]}$, 本研 究选择中国西北内陆省份甘肃为研究案例, 采用静态耦合协调度模型与动态耦合过程分析相结合的方法, 研 究中国西部典型区域的社会经济发展与自然生态环境质量间的协调发展程度以及演变规律, 并重点讨论社会 经济发展趋势与生态环境质量变化趋势的动态耦合过程,为甘肃省生态环境保护与社会经济发展协调的政策 体系提供可靠的理论支撑。

\section{1 研究方法}

\section{1 综合评价指数}

综合评价指数的计算采用对综合指标体系内各项指标值的加权平均。本研究中, 首先采用熵值法对指标 体系的权重进行客观赋值,通过计算指标项信息量获得指标的信息熵,确定各指标权重,信息熵是对系统无序 程度的度量方式 ${ }^{[19]}$, 若系统该指标的变化程度越大, 那么其信息摘就越小,该指标提供的信息量就越大。因 此, 根据系统各个指标值的变异程度, 可以得到各个指标的权重值。

(1) 标准化指标值 ${ }^{[20]}$, 
其中, $n$ 为评价样本的总数。

$$
f_{i j}=\frac{r_{i j}}{\sum_{j}^{n} r_{i j}}
$$

(2) 计算第 $i$ 项指标的信息熵值,

$$
H_{i}=-k \sum_{j=1}^{n} f_{i j} \ln f_{i j}
$$

其中, 若 $f_{i j}=0$ 时, 则假设 $f_{i j} \ln f_{i j}=0$, 且假设 $k=1 / \ln n$, 因此有 $0<H_{i}<1$ 。

(3) 计算第 $i$ 项指标的基于信息熵的权重

$$
W_{i}=\frac{1-H_{i}}{m-\sum_{i=1}^{m} H_{i}}
$$

其中, $\sum_{i=1}^{m} W_{i}=1,0<W_{i}<1, m$ 为评价指标体系的指标总数。

进而,利用指标去那种与指标量化值计算自然生态系统与社会经济系统的综合评价指数,其计算公式为:

$$
f(x) \text { or } f(y)=\sum_{i=1}^{n, m} W_{i} f_{i j}
$$

其中, $f(x)$ 是自然生态环境系统的综合评价指数, $f(\mathrm{y})$ 是社会经济系统的综合评价指数。

\section{2 耦合协调度模型}

\subsection{1 耦合度}

耦合度用于分析两个或两个以上系统或运动形态之间通过相互作用进而产生影响的现象和程度。本研 究中,耦合度即为甘肃省社会经济系统与生态环境系统的耦合程度, 反映甘肃省社会经济系统与生态环境系 统之间的耦合关系 ${ }^{[21]}$ 。计算公式如下:

$$
C=\sqrt{\frac{f(x) \times f(y)}{[f(x)+f(y)]^{2}}}
$$

其中, $C$ 是系统耦合度, $C \in[0,1], f(x)$ 是自然生态环境系统的综合评价指数, $f(y)$ 是社会经济系统的综 合评价指数, $f(x)$ 和 $f(y)$ 都基于综合评估模型计算。

本研究中, $C=0$ 时,系统耦合度最小,认为甘肃省生态环境系统与社会经济系统要素间无关联,整个系统 朝无序状态发展。考虑到甘肃省与陕西省安塞的地域及发展特征存在一定的相似性, 本研究中系统耦合度的 分级参考文章《陕北安塞县生态与经济系统耦合协调发展》中耦合度的分级标准 ${ }^{[23]}$ 。 $C \in(0,0.35]$ 时, 社会 经济发展处于较低水平,生态环境承载力强,为弱耦合; $C \in(0.35,0.65]$ 时,社会经济发展水平提高,生态环 境承载力下降, 为中度耦合; $C \in(0.65,0.85]$ 时,社会经济发展水平与生态环境承载力水平互相靠近, 为较 强耦合; $C \in(0.85,1)$ 时,社会经济发展水平与生态环境承载力水平彼此接近, 为极强耦合; $C=1$ 时, 社会经 济系统与生态环境系统达到良性共振,耦合度最高, 系统整体向有序发展。

\subsection{2 综合发展指数}

综合发展指数反映的是甘肃省社会经济发展与生态环境保护的综合水平,由自然生态环境系统综合评价 指数 $f(x)$ 和社会经济系统综合评价指数 $f(\mathrm{y})$ 加权而来。计算公式如下:

$$
T=\alpha f(x)+\beta f(y)
$$

其中, $T$ 为系统综合发展指数, $\alpha$ 和 $\beta$ 分别是自然生态环境综合评价指数和社会经济系统综合评价指数在评 价指标体系中的权重。

\subsection{3 耦合协调度指数}

耦合度虽然能定量分析各子系统间的相互影响程度并预警系统的发展秩序, 但是不能反映研究系统的综 
合发展水平, 难以测度研究系统的整体功效 ${ }^{[22]}$ 。因此, 必须构建耦合协调度模型来评判各子系统的优劣等 级,避免出现社会经济发展与生态环境系统水平都比较低,但耦合度高的情况。计算公式如下:

$$
D=\sqrt{C \times T}
$$

其中, $D$ 为耦合协调度, $D \in[0,1]$, 在一定的社会经济发展水平和生态环境状况下,生态环境与社会经济水 平的复合效益越大, 则说明系统整体的发展更加协调, 因而, $D$ 越接近 1 说明系统整体的耦合协调程度越高, 反之说明系统耦合协调程度低。

结合已有研究文献综述 ${ }^{[23]}$, 考虑耦合协调度与其系统综合评价指数的特征, 综合反映甘肃省社会经济发 展与生态环境的耦合协调类型特征( 如表 1 )。

\section{表 1 甘肃省社会经济与生态环境耦合协调类型特征}

Table 1 Coupling coordination types and characteristic of social-economy and eco-environment

\begin{tabular}{cccc}
\hline $\begin{array}{c}\text { 耦合协调度分级 } \\
\text { Coupling coordination degree }\end{array}$ & $\begin{array}{c}\text { 类型 } \\
\text { Category }\end{array}$ & $\begin{array}{c}\text { 耦合协调度分级 } \\
\text { Coupling coordination degree }\end{array}$ & $\begin{array}{c}\text { 类型 } \\
\text { Category }\end{array}$ \\
\hline $0<D \leqslant 0.1$ & 严重失调 & $0.5<D \leqslant 0.6$ & 勉强失调 \\
$0.1<D \leqslant 0.2$ & 重度失调 & $0.6<D \leqslant 0.7$ & 初级协调 \\
$0.2<D \leqslant 0.3$ & 中度失调 & $0.7<D \leqslant 0.8$ & 中度协调 \\
$0.3<D \leqslant 0.4$ & 轻度失调 & $0.8<D \leqslant 0.9$ & 良好协调 \\
$0.4<D \leqslant 0.5$ & 濒临失调 & $0.9<D \leqslant 1.0$ & 优质协调 \\
\hline
\end{tabular}

进一步的, 深人分析系统综合评价指数的特征,耦合协调度类型可被分为三类, 当 $f(x)>f(y)$ 时,耦合 协调度类型为社会经济发展滞后型; 当 $f(x)<f(y)$ 时,耦合协调度类型为生态环境滞后型; 当 $f(x)=f(y)$ 时,耦合协调度类型为同步发展型。

\section{3 指标体系与数据}

甘肃省生态环境与社会经济系统协调发展的综合指标体系主要由自然生态环境系统与社会经济系统构 成,指标选取综合考虑其代表性、客观性以及对社会发展的描述贴近程度、可比性等原则,结合甘肃省社会经 济发展现状与生态环境实际特征, 参考已有相关研究成果 ${ }^{[24-26]}$, 构建能够综合反映甘肃省生态环境质量与社 会经济发展水平的综合评价指标体系(如表 2)。其中自然生态环境系统包括自然资源供给、自然生态条件、 生态环境压力、生态环境胁迫、生态环境风险等一级指标,具体选择年均降水量、年平均气温、人均可用水资源 量、植被覆盖度、建成区绿化率等 16 个指标; 社会经济系统包括经济发展指数、社会发展指数、城市生活指数 等一级指标,具体选择地区生态总值、人均财政收人、社会固定资产投资额等 11 个指标。各指标的权重福祉, 采用熵权法进行确定,并经过加权求和获得甘肃省自然生态环境和社会经济系统的综合指标值。

\section{2 研究区域与数据来源}

\section{1 研究区概况}

甘肃地处我国西北部内陆地区, 位于黄河上游, 黄土高原、内蒙古高原和青藏高原的交汇地带 ${ }^{[27]}$ 。区域 内气候类型复杂, 全年降水量少, 境内植被覆盖度低, 水资源条件差。甘肃自然生态环境多样,脆弱生态区众 多, 水土流失和土地荒漠化程度较高, 生态环境条件恶劣。在社会经济方面, 经济水平整体较低,贫困率高, 发 展难度高。随着甘肃社会经济的快速发展, 工业和人口呈现向城市大规模聚集的趋势,生态环境与社会经济 发展的矛盾日趋凸显, 甘肃在生态环境与社会经济耦合发展研究方面具有代表性意义。

\section{2 数据来源}

本研究以 2007-2017 年为研究时段,数据主要来源于《中国统计年鉴 (2008-2018)》、《甘肃省统计年鉴 (2008-2018)》、《中国环境统计年鉴 (2008-2018)》、《中国城市统计年鉴 $(2008-2018)$ 》、甘肃省国民经济 和社会发展统计公报 (2008-2018) 等国家和地方公开发布的统计资料,污染物排放数据主要来自于第二次 
全国污染物普查, 个别缺失数据采用移动平均进行模拟。数据归一化采用极差变换法对各指标数据进行 量化。

\section{表 2 综合指标体系及指标权重}

Table 2 The integrated index systems and index weights

\begin{tabular}{|c|c|c|c|c|c|}
\hline $\begin{array}{l}\text { 宏观系统 } \\
\text { System }\end{array}$ & $\begin{array}{l}\text { 一级指标 } \\
\text { Sub-system }\end{array}$ & $\begin{array}{c}\text { 熵权法权重 } \\
\text { Weight by } \\
\text { entropy method }\end{array}$ & $\begin{array}{l}\text { 二级指标 } \\
\text { Specific indicator }\end{array}$ & $\begin{array}{c}\text { 指标属性 } \\
\text { Indicator attribute }\end{array}$ & $\begin{array}{c}\text { 熵权法权重 } \\
\text { Weight by } \\
\text { entropy method }\end{array}$ \\
\hline 自然生态环境 & 自然资源供给 & 0.0940 & 年均降水量 & 正 & 0.0369 \\
\hline Natural ecological & & & 年平均气温 & 正 & 0.0355 \\
\hline \multirow[t]{14}{*}{ environment } & & & 人均可用水资源量 & 正 & 0.0216 \\
\hline & 自然生态条件 & 0.1271 & 植被覆盖度 & 正 & 0.0271 \\
\hline & & & 建成区绿化率 & 正 & 0.0209 \\
\hline & & & 人均绿地面积 & 正 & 0.0453 \\
\hline & & & 环境空气质量综合指数 & 正 & 0.0338 \\
\hline & 生态环境压力 & 0.2001 & 单位 GDP 能耗 & 逆 & 0.0327 \\
\hline & & & 人均耕地面积 & 逆 & 0.0775 \\
\hline & & & 工业废水排放量 & 逆 & 0.0570 \\
\hline & & & 工业 $\mathrm{SO}_{2}$ 排放量 & 逆 & 0.0329 \\
\hline & & & 工业固体废弃物排放量 & 逆 & 0.0483 \\
\hline & & & 农业化肥投人量 & 逆 & 0.0604 \\
\hline & & & 集中式污水处理率 & 正 & 0.0141 \\
\hline & 生态环境风险 & 0.0618 & 工业危险废物产生量 & 逆 & 0.0179 \\
\hline & & & 工业危险废物处置率 & 逆 & 0.0438 \\
\hline 社会经济系统 & 经济发展指数 & 0.1132 & 地区生产总值 & 正 & 0.0367 \\
\hline \multirow[t]{10}{*}{ Social economic system } & & & 人均财政收人 & 正 & 0.0362 \\
\hline & & & 社会固定资产投资总额 & 正 & 0.0405 \\
\hline & 社会发展指数 & 0.1191 & 人口密度 & 逆 & 0.0249 \\
\hline & & & 居民可支配收人 & 正 & 0.0431 \\
\hline & & & 各类学校在校人数 & 正 & 0.0213 \\
\hline & & & 各类医院床位数 & 正 & 0.0298 \\
\hline & 城市生活指数 & 0.1620 & 城市公共服务用水量 & 逆 & 0.0380 \\
\hline & & & 城市居民家庭用水量 & 逆 & 0.0353 \\
\hline & & & 城市人均公园绿地面积 & 正 & 0.0477 \\
\hline & & & 空气质量优良天数 & 正 & 0.0409 \\
\hline
\end{tabular}

\section{3 结果}

3.1 甘肃省自然生态环境系统与社会经济系统综合发展指数演变特征

\subsection{1 自然生态环境综合指数}

由图 1 可知,甘肃省的自然环境质量指数在 2007-2017 年间呈先波动下降后逐步上升的变化趋势， 2012-2014 年间急剧下降,说明该时期内生态环境整体面临的压力加大。后在 2015 年情况得到较大改善， 此后,生态环境质量不断向好。

自然环境质量系统分类指标中,生态环境压力的波动趋势与自然环境质量波动趋势基本一致,所占指标 权重在自然环境质量系统中最高为 0.2 , 这在一定程度上反映出废水和废气的排放以及耗能与耕地面积的增 加是影响甘肃省生态环境质量的主要因素, 即生态环境质量的突然升高主要是由于期间污染排放量显著增 加。由此说明,甘肃省在经过了一次较大的自然环境波动后,加强了对自然环境的保护并取得显著的环境污 


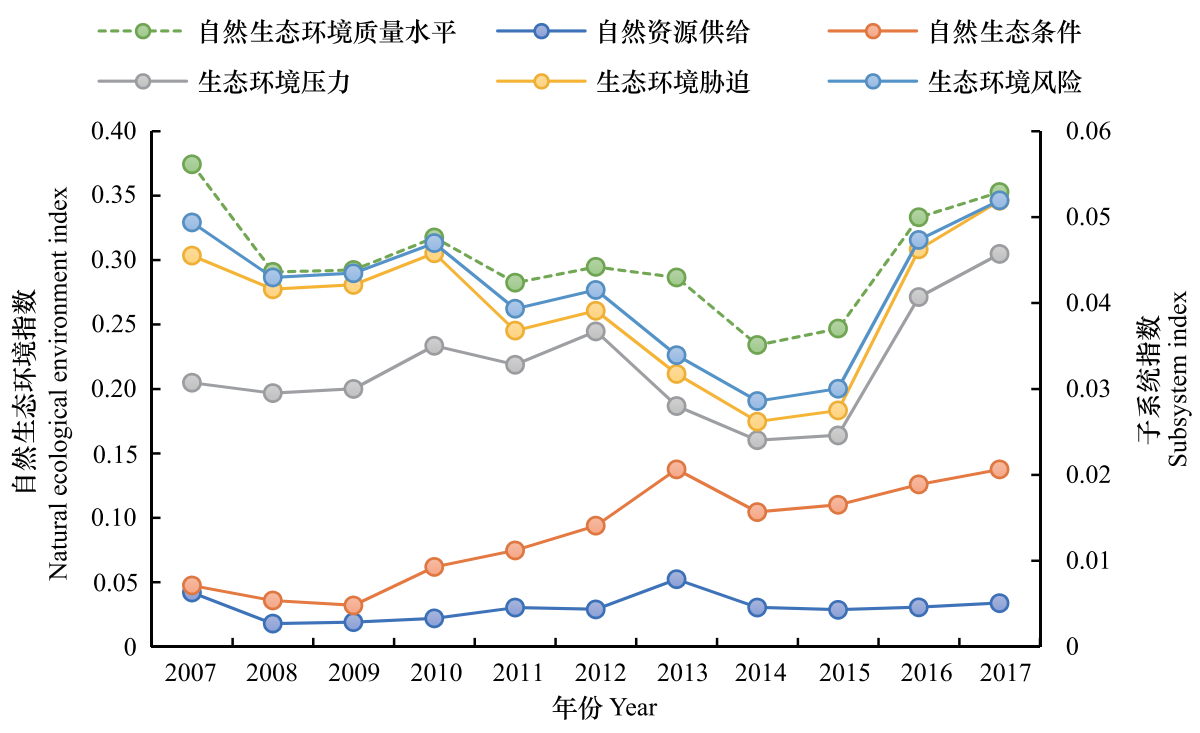

图 1 甘肃省自然生态环境指数变化趋势

Fig.1 The tendency of natural ecological environment index in 2007 to 2017

染治理成效。

3.1.2 社会经济综合指数

由图 2 可知,甘肃省社会经济发展水平自然环境系 统的综合水平在 2007-2017 年间整体呈现上升趋势, 由 2007 年的 0.189 上升到 2017 年的 0.320 ,但自 2014 年来增速有所放缓呈现出小幅波动。由此说明 10 年 间,随着城镇化的发展, 甘肃省经济发展水平不断提升， 人民生活质量不断提高, 2014 年后经济增速有所放缓。

在社会经济系统分类指标中,三个子系统的权重相 对平均。其中, 经济发展指数、社会发展指数上升速度 较快,带动了经济的快速发展, 城市生活指数与社会经 济系统综合指数整体波动情况较为一致。

3.2 甘肃省自然生态环境与社会经济耦合协调度

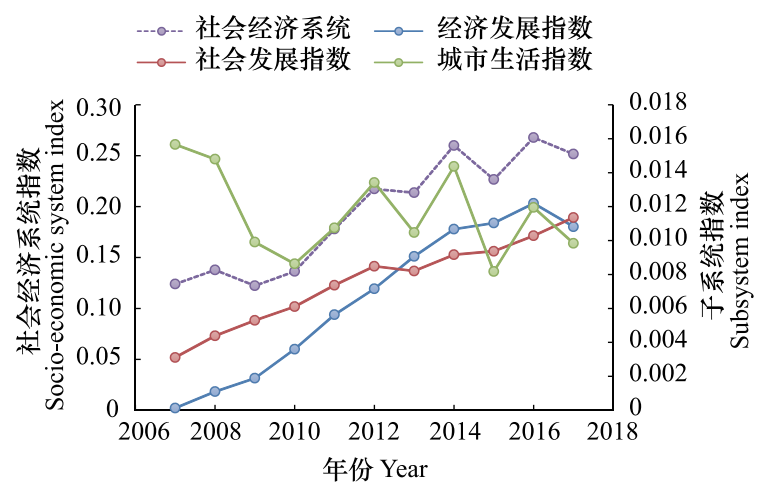

图 2 甘肃省社会经济综合指数变化趋势

Fig.2 The tendency of social-economic index in 2007 to 2017

为了更好的分析甘肃省自然生态系统和社会经济系统的综合指数的变化情况及评判经济增长、生态环境 交互耦合的协调程度。将二者看作两个系统,借助耦合和协调的理论模型,利用公式计算得到自然生态系统 和社会经济系统的耦合度 $\mathrm{C}$ 以及耦和协调度 $\mathrm{D}$,结果见表 3 。

由耦合度可知, 2007-2017 年, 甘肃省的社会经济与自然生态环境质量的发展状态从失调阶段逐步过渡 到协调阶段,说明这一耦合过程正从磨合阶段向着高水平有序状态稳固发展。

由表 3 和图 3 可知, 2007-2017 年甘肃省社会经济与生态环境的耦合协调度水平处在 $0.37-0.54$ 之间, 整体在向好的方向转变, 经历了从轻度失调到濒临失调再到勉强失调的过程,拐点分别为 2010 年、2015 年。 说明 10 年间,甘肃省生态环境与经济发展的耦合协调性有所改善。此外,对比城市化系统与生态环境系统的 综合指数得出协调类型, 可知除 2014-2015 年间为城市化滞后型, 其余皆为生态环境滞后型。由此反映出甘 肃省在十年间甘肃省自然生态环境的质量是制约甘肃省城市化与自然生态环境耦合协调发展的因素,整体的 社会经济发展是处于粗放型阶段,以牺牲生态环境为代价的发展经济。具体表现为: 
表 3 甘肃省自然生态环境与社会经济耦合协调度评价结果

Table 3 The coupling coordination degree of natural ecological environment and social-economy of Gansu Province

\begin{tabular}{|c|c|c|c|c|c|c|c|c|}
\hline $\begin{array}{l}\text { 年份 } \\
\text { Year }\end{array}$ & $\begin{array}{c}\text { 自然生态 } \\
\text { 环境指数 } \\
\text { Natural } \\
\text { ecological } \\
\text { environment } \\
\text { index }\end{array}$ & $\begin{array}{c}\text { 社会经济 } \\
\text { 发展指数 } \\
\text { Social } \\
\text { economic } \\
\text { index }\end{array}$ & $\begin{array}{c}\text { 综合发 } \\
\text { 展指数 } \\
\text { Integrated } \\
\text { development } \\
\text { index }\end{array}$ & $\begin{array}{c}\text { 耦合度 } \\
\text { Coupling } \\
\text { degree }\end{array}$ & $\begin{array}{c}\text { 耦合类型 } \\
\text { Coupling } \\
\text { type }\end{array}$ & $\begin{array}{c}\text { 耦合协调度 } \\
\text { Coupling } \\
\text { coordination } \\
\text { degree }\end{array}$ & $\begin{array}{c}\text { 协调状态 } \\
\text { Coordination } \\
\text { status }\end{array}$ & $\begin{array}{c}\text { 协调类型 } \\
\text { Coordination } \\
\text { category }\end{array}$ \\
\hline 2007 & 0.3743 & 0.1240 & 0.6828 & 0.5588 & 中耦合 & 0.3731 & 轻度失调 & 轻度失调生态环境滞后型 \\
\hline 2008 & 0.2909 & 0.1379 & 0.6325 & 0.7615 & 较强耦合 & 0.4041 & 濒临失调 & 濒临失调生态环境滞后型 \\
\hline 2009 & 0.2923 & 0.1224 & 0.6057 & 0.6922 & 较强耦合 & 0.3788 & 轻度失调 & 轻度失调生态环境滞后型 \\
\hline 2010 & 0.3176 & 0.1364 & 0.6531 & 0.7067 & 较强耦合 & 0.4005 & 濒临失调 & 濒临失调生态环境滞后型 \\
\hline 2011 & 0.2824 & 0.1780 & 0.6308 & 0.8997 & 极强耦合 & 0.4551 & 濒临失调 & 濒临失调生态环境滞后型 \\
\hline 2012 & 0.2947 & 0.2174 & 0.7060 & 0.9549 & 极强耦合 & 0.4945 & 濒临失调 & 濒临失调生态环境滞后型 \\
\hline 2013 & 0.2866 & 0.2137 & 0.6167 & 0.9580 & 极强耦合 & 0.4895 & 濒临失调 & 濒临失调生态环境滞后型 \\
\hline 2014 & 0.2341 & 0.2599 & 0.6279 & 0.9945 & 极强耦合 & 0.4956 & 濒临失调 & 濒临失调城市化滞后型 \\
\hline 2015 & 0.2469 & 0.2266 & 0.5861 & 0.9963 & 极强耦合 & 0.4857 & 濒临失调 & 濒临失调城市化滞后型 \\
\hline 2016 & 0.3333 & 0.2678 & 0.8177 & 0.9764 & 极强耦合 & 0.5417 & 勉强失调 & 勉强协调生态环境滞后型 \\
\hline 2017 & 0.3528 & 0.2517 & 0.8395 & 0.9448 & 极强耦合 & 0.5344 & 勉强失调 & 勉强协调生态环境滞后型 \\
\hline
\end{tabular}

(1) $2007-2010$ 年, 轻度失调, 这一阶段协调指数 处于轻微波动但幅度不大。这是由于此阶段正是甘肃 省以粗放型发展模式依靠工业化带动城市化的快速发 展, 人口增加、耕地面积减少、工业 “三废” 的大量排放, 使得污染物排放的速度大于其生态环境自身的溶解能 力等,加之期间甘肃水资源贫乏、干旱少雨、植被稀疏、 水蚀风蚀活跃,生态环境本底脆弱,生态系统的稳定性 差, 环境承载力有限, 很大程度上限制了城镇化与生态 环境的协调发展。

(2) 2011-2015 年, 濒临协调, 这一阶段协调指数 先快速上升后很长一段时间稳定于 0.5 左右。这一时 期地方政府将生态环境建设纳人城市协调发展的体系 中,对城市布局进行合理规划, 扩大绿地面积, 提高生态

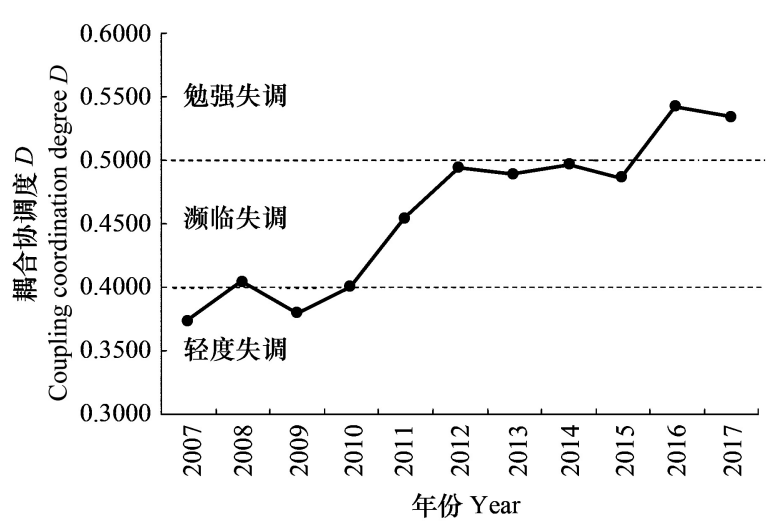

图 3 甘肃省耦合协调度演变过程及类别

Fig.3 Trends of coupling coordination and category in Gansu Province 系统的自我调节能力,有效调节了城镇化与生态环境的 协调关系, 反映出城市生态经济耦合协调发展由粗放逐渐向集约、绿色循环模式渐趋形成,生态环境逐渐 修复;

（3）2016-2017 年,勉强失调,这一阶段协调指缓慢上升。表明甘肃自然生态环境的保护与治理取得一 定成效, 自然生态环境与社会经济已经有转向协调发展的趋势, 且经济对于环境修复支撑作用逐渐增强, 二者 之间出现良性耦合。

\section{4 讨论}

4.1 基于剪刀差分析的甘肃省自然生态环境与社会经济发展增长速率的耦合过程

甘肃省生态环境质量与社会经济发展过程具有不一致的变化趋势,为更好地理解生态环境变化与社会经 济发展过程的差异, 本研究采用剪刀差分析方法对生态环境质量与社会经济发展的变化速率构建切线夹 角 ${ }^{[28]}$,分析其相互之间的变化差异。计算方法为: 


$$
\begin{gathered}
f^{\prime}(x)=\frac{d x}{d t}, f^{\prime}(y)=\frac{d y}{d t} \\
\theta=\arctan \left|\frac{f^{\prime}(x)-f^{\prime}(y)}{1+f^{\prime}(x) \cdot f^{\prime}(y)}\right|,\left(0<\theta<\frac{\pi}{2}\right)
\end{gathered}
$$

其中, $f^{\prime}(x)$ 是自然生态环境系统对年份的变化趋势, $f^{\prime}(y)$ 是社会经济系统对年份的变化趋势, $\theta$ 是 $f(x)$ 和 $f(y)$ 两条曲线在给定时刻的两切线夹角, $\theta$ 越小说明 $f(x)$ 和 $f(y)$ 变化趋势之间的差异越小。

由表 4 和图 4 可以看出,甘肃省自然环境和社会经济变化速率的剪刀差的演变过程可以分为三个阶段:

表 4 甘肃省自然生态环境与社会经济发展的增长速率及剪刀差

\begin{tabular}{|c|c|c|c|c|c|}
\hline $\begin{array}{l}\text { 年份 } \\
\text { Year }\end{array}$ & $\begin{array}{c}\text { 自然生态环 } \\
\text { 境系统指数 } \\
\text { Natural ecological } \\
\text { environment index }\end{array}$ & $\begin{array}{l}\text { 社会经济系统指数 } \\
\text { Social economic index }\end{array}$ & $\begin{array}{c}\text { 自然生态环境 } \\
\text { 指数增长速率 } \\
\text { Growth rate of } \\
\text { natural ecological } \\
\text { environment index }\end{array}$ & $\begin{array}{c}\text { 社会经济指数 } \\
\text { 增长速率 } \\
\text { Growth rate of } \\
\text { social economic index }\end{array}$ & $\begin{array}{c}\text { 剪刀差 } \\
\text { Scissors } \\
\text { differential }\end{array}$ \\
\hline 2008 & 0.2909 & 0.1379 & -0.2227 & 0.1124 & 8.3709 \\
\hline 2009 & 0.2923 & 0.1224 & 0.0047 & -0.1127 & 9.3187 \\
\hline 2010 & 0.3176 & 0.1364 & 0.0864 & 0.1145 & 9.8538 \\
\hline 2011 & 0.2824 & 0.1780 & -0.1108 & 0.3051 & 5.679 \\
\hline 2012 & 0.2947 & 0.2174 & 0.0436 & 0.2214 & 4.1582 \\
\hline 2013 & 0.2866 & 0.2137 & -0.0276 & -0.0170 & 3.9309 \\
\hline 2014 & 0.2341 & 0.2599 & -0.1833 & 0.2166 & 1.398 \\
\hline 2015 & 0.2469 & 0.2266 & 0.0549 & -0.1282 & 1.1007 \\
\hline 2016 & 0.3333 & 0.2678 & 0.3500 & 0.1818 & 3.4411 \\
\hline 2017 & 0.3528 & 0.2517 & 0.0584 & -0.0603 & 5.3065 \\
\hline
\end{tabular}

Table 4 Growth rate of natural eco-environment and social- economy system and their scissors differential in Gansu Province

1) 2008 -2010 年, 剪刀差角度由 $8.3709^{\circ}$ 上升到 $9.8538^{\circ}$, 该时段自然环境指数与社会经济指数均较为 平稳。该时期反映了甘肃省自然生态环境状况与社会 经济发展间的差异较大,互相无明显的限制。

2) 2011－2015 年,剪刀差角度迅速下降到 $1.1007^{\circ}$, 可知自然环境指数与社会经济指数的差距在迅速下降。 该时期生态环境状况相对较好, 而社会经济水平相对落 后, 但自然生态环境的变化速率整体呈现负增长,而社 会经济指数增速则有所提升。说明该时期社会经济对 生态环境的压力正在逐步加重,正在以损害生态支撑能 力为代价的来发展经济。

3) 2016-2017 年, 剪刀差角度上升到 $5.3065^{\circ}$,由 此说明该时段甘肃省社会经济继续快速发展,生态支撑

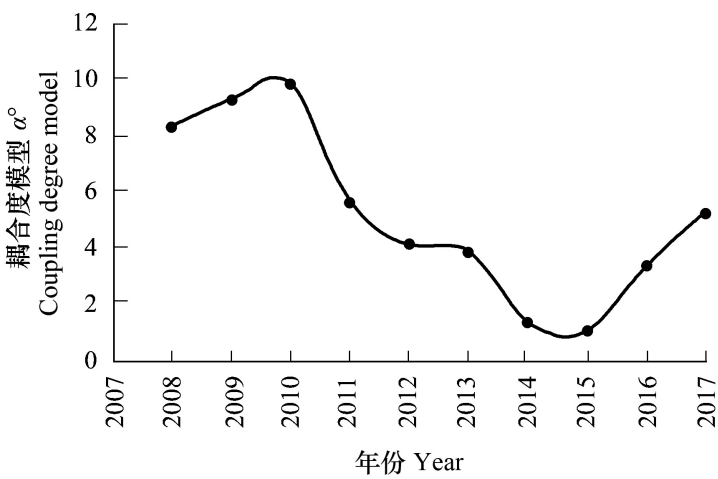

图 4 自然生态环境系统与社会经济系统的剪刀差演变过程

Fig.4 Trends of scissors differential between natural ecoenvironmental system and social-economic system 能力有所回升,印证了甘肃省政府对生态环境加以重视,生态环境得到了保护。

4.2 甘肃省自然生态环境与社会经济发展过程的动态耦合分析

考虑甘肃省自然生态环境系统与社会经济系统的交互胁迫关系,讨论各子系统受自身和另一个子系统影 响下的演化状态, 通过分析自然生态环境系统变化速率与社会经济系统变化速率在二维平面上构成的投影轨 迹的夹角 $\varphi$,作为耦合模型角度来判断 ${ }^{[29]}$, 系统间的周期性动态耦合过程。

$$
\varphi=\arctan \left(\frac{f^{\prime}(x)}{f^{\prime}(y)}\right),(-\pi<\varphi<\pi)
$$


甘肃省社会经济与生态环境的耦合度处于剪刀差耦合度模型的第 I 区, 其角度范围在 $-90^{\circ}<\varphi<45^{\circ}$ 间波 动, 说明近 10 年甘肃省经济的发展已经从不受生态环境约束, 转变为受约束状(如图 5)。具体可分为两种:

(1) 当 $-90^{\circ}<\varphi \leqslant 0^{\circ}$ 时, 系统处于低级协调共生阶段。2008-2009,2011,2014-2015,2017。该阶段经济 发展缓慢,且基本不受生态环境的限制和约束,经济发展对生态环境的影响也几乎为零。

(2) 当 $0^{\circ}<\varphi \leqslant 45^{\circ}$ 时, 系统处于初级协调发展阶段。2009-2011, 2012-2014, 2015-2016。V $(x)<$ $V(y)$, 经济发展速度小于环境演化速度, 经济发展已经开始显现出对生态环境的胁迫作用,生态环境制约了 经济发展。

两种状态呈现交替出现,周期大约为 2-3 年,这主要是由于两系统变化的速率不同,自然生态环境对城 市化的响应较为明显, 具有一定的滞后性。

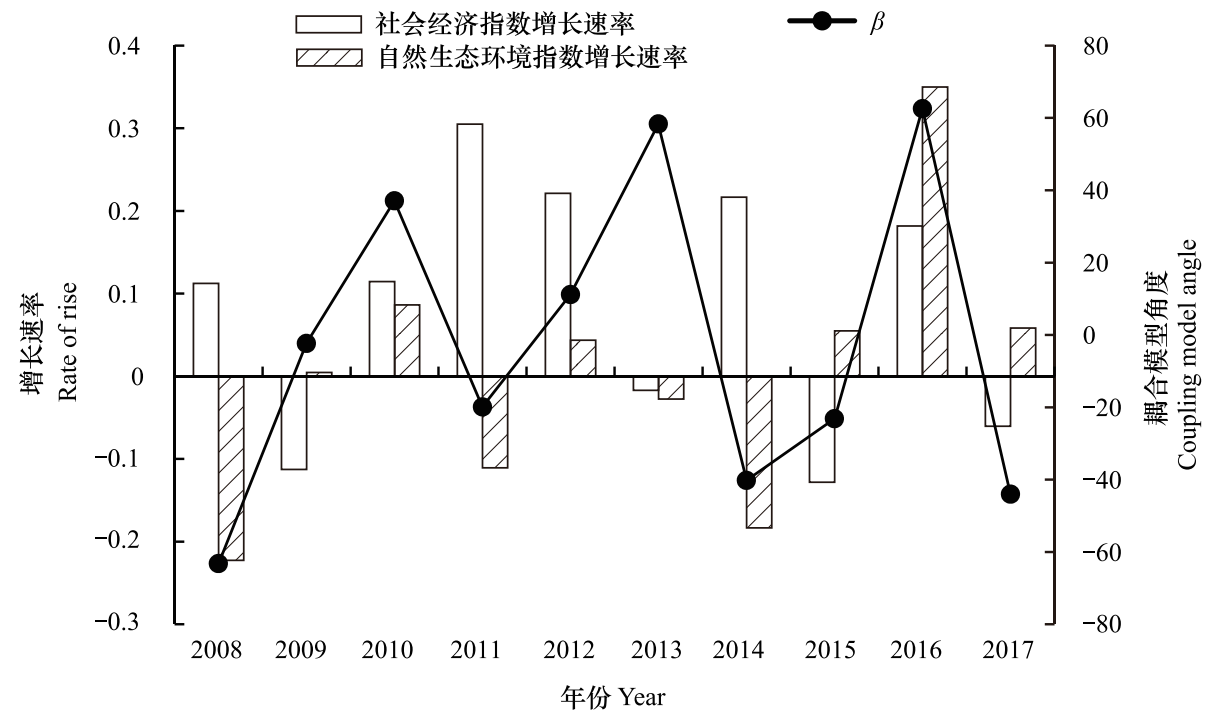

图 5 甘肃省自然生态环境与社会经济发展的剪刀差

Fig.5 The scissors of the natural ecological environment and the social and economic development in Gansu Province

具体而言从增长速率来看具体可以分为两个阶段:

(1) 自然生态环境的发展速度小于社会经济的发展速度:2007-2014 年

(2) 自然生态环境的发展速度大于社会经济的发展速度:2015-2017 年

初期经济发展缓慢,且基本不受生态环境的限制和约束,经济发展对生态环境的影响也几乎为零。但是 甘肃省社会经济的发展速度相对于生态环境发展速度越来越快,经济虽然得到了长足的发展,但其对环境的 依赖和消耗也越来越严重, 使得生态环境对经济快速发展的支撑能力愈发不足, 从而制约了经济发展使得社 会经济发展速度需要放缓。由此也就解释了自然生态环境的滞后性,说明了为什么两种状态呈现交替出现。

自然生态环境的增速自 2015 年开始转变为高于社会经济的发展速度, 由此表明甘肃省政府已经意识到 经济发展对环境的影响并展开了一定的产业结构优化和自然环境保护,初步的效果在这一年开始显现。

\section{5 结论}

本研究对甘肃省的社会经济发展与当地自然生态环境保护之间的耦合协调状况开展分析, 采用自然生态 环境与社会经济耦合协调度评估模型对甘肃省 2007-2017 年间的耦合协调程度进行计算,并分别基于剪刀 差和耦合模型分析甘肃省自然生态系统与社会经济发展的动态耦合过程。2007-2017 年间, 甘肃省自然环 境质量指数波动下降后逐步上升,社会经济发展水平水平整体呈上升趋势, 自然生态环境与社会经济耦合协 调度在轻度失调到勉强失调之间, 耦合协调度波动增加。2015 年以来, 随着自然生态环境质量的提升, 甘肃 
省社会经济与自然生态环境直接的协调过程已逐渐呈现效果,社会经济发展对生态环境的影响与相互促进作 用开始显现。

\section{参考文献 (References) :}

［1］乔标, 方创琳. 城市化与生态环境协调发展的动态耦合模型及其在干旱区的应用. 生态学报, 2005, 25(11):3003-3009.

[ 2 ] 李双江, 胡亚妮, 崔建升, 沈洪艳. 石家庄经济与人居环境耦合协调演化分析. 干旱区资源与环境, 2013, 27(4):8-15.

[ 3 ] 江红莉, 何建敏. 区域经济与生态环境系统动态耦合协调发展研究———基于江苏省的数据. 软科学, 2010, 24(3):63-68.

[ 4] 方创琳, 周成虎, 顾朝林, 陈利顶, 李双成. 特大城市群地区城镇化与生态环境交互耦合效应解析的理论框架及技术路径. 地理学报, 2016, 71(4) : 531-550.

[ 5 ] 李泪梅, 周敬宣, 张涃, 肖人涁. 城市生态系统协调发展仿真研究——以武汉市为例. 环境科学学报, 2008(12): 2605-2613.

[ 6 ] Clark W C. Sustainability science: A room of its own. Proceedings of the National Academy of Sciences, 2007, 104(6) : 1737-1738.

[ 7 ] Clark W, Crutzen P J, Schellnhuber H J. Science for global sustainability: toward a New Paradigm. Working Paper Series, 2005, 15(35): 837-868.

[ 8 ] Levrel H, Kerbiriou C, Couvet D, Weber J. OECD pressure-state-response indicators of managing biodiversity: A realistic per-spective for a French biosphere reserve. Biodiversity and Conservation, 2009, 18(7): 1719-1732.

[ 9 ] Jill L, Caviglia H, Dustin C. Taking the "U” out of Kuznets: a comprehensive analysis of the EKC and environmental degradation. Ecological Economics, 2009, 68(4): 1149-1159.

[10] Grossman G G, Krueger A B. Economic growth and the environment. Quarterly Journal of Economics, 1995, 110(2) : 353-377.

[11] 左其亭, 陈嘻. 社会经济-生态环境耦合系统动力学模型. 上海环境科学, 2001(12): 592-594+626.

[12] 红丽, 薛惠锋, 张哲, 李献峰. 经济一环境系统影响因子耦合度分析. 河北工业大学学报, 2008(03): 84-89.

[13］任志远, 徐茜, 杨忍. 基于耦合模型的陕西省农业生态环境与经济协调发展研究. 干旱区资源与环境, 2011, 25(12): 14-19.

[14] 刘耀须. 区域城市化与生态环境耦合特征及机制: 以江苏省为例. 经济地理, 2006, 26(3) : 456-462.

[15］黄金川, 方创琳. 城市化与生态环境交互耦合机制与规律性分析. 地理研究, 2003, 22(2) : 211-220.

[16] 方创琳. 京津冀城市群协同发展的理论基础与规律性分析. 地理科学进展, 2017, 36(1)：15-24.

[17］方创琳, 杨玉梅. 城市化与生态环境交互耦合系统的基本定律. 干旱区地理, 2006, 29(1)：1-8.

［18］毕国华, 杨庆媛, 刘 苏. 中国省域生态文明建设与城市化的耦合协调发展. 经济地理, 2017, 37(1)：51-58.

[19］李元年. 基于熵理论的指标体系区分度测算与权重设计. 2008. 博士学位论文. 南京: 南京航空航天大学.

[20］王春枝. 综合评价指标笁选及预处理的方法研究. 统计教育, 2007, 03: 15-16.

[21］黄金川, 方创琳. 城市化与生态环境交互耦合机制与规律性分析. 地理研究, 2003(02): 211-220.

[22]王明全, 王金达, 刘景双, 顾康康. 吉林省西部生态支撑能力与社会经济发展的动态耦合. 应用生态学报, 2009, 20(01)：170-176.

[23] 马亚亚, 刘国彬, 张超, 王杰. 陕北安塞县生态与经济系统耦合协调发展. 生态学报, 2019, 39(18): 6840-6849.

[24] Yuan C Q, Liu S F, Xie N M. The impact on Chinese economic growth and energy consumption of the Global Financial Crisis: an in-output analysis. Energy, 2010, 35(4): 1805-1812.

[25] 张青峰, 吴发启, 王力, 王健. 黄土高原生态与经济系统耦合协调发展状况. 应用生态学报, 2011, 22(06): 1531-1536.

[26] 陈晓红, 周宏浩. 城市化与生态环境关系研究热点与前沿的图谱分析. 地理科学进展, 2018, 37(9): 1171-1185.

[27］杨亮洁,杨永春. 甘肃省资源环境承载力时空分异. 生态学报, 2017, 37(20)：7000-7017.

[28] 韩瑞玲, 佟连军, 佟伟铭, 于建辉. 沈阳经济区经济与环境系统动态耦合协调演化. 应用生态学报, 2011, 22(10): 2673-2680.

[29] 熊建新, 陈端吕, 彭保发, 邓素婷, 谢雪梅. 洞庭湖区生态承载力系统耦合协调度时空分异. 地理科学, 2014, 34(09): 1108-1116. 